ROBERT J. GORDON

Northwestern University and the

National Bureau of Economic Research

\title{
The "End-of-Expansion" Phenomenon in Short-Run Productivity Behavior
}

THE STARTLING DECLINE in U.S. aggregate labor productivity during the first three quarters of 1979 (a 2.3 percent decline in the nonfarm business sector at an annual rate) adds new urgency to the continuing concern about U.S. productivity behavior. Several important recent studies have documented a slowdown in the secular growth rate of productivity that has taken place in two stages, the first beginning after 1965 or 1966 and the second after 1973, and most studies appear to leave the causes of a large portion of the deceleration as an unresolved puzzle. ${ }^{1}$ Does the experience of 1979 suggest that a third stage of the secular slowdown has begun, or is this recent behavior consistent with previous occurrences at the same stage of the business cycle?

Many studies of the short-run cyclical behavior of labor productivity have been by-products of larger studies of secular trends. In the work of Perry and Nordhaus, for instance, a cyclical correction was required to construct measures of aggregate "normal" or "potential" productivity for studies of long-term trends and the sources of shifts in these trends. ${ }^{2}$ This

Note: The author is grateful to the National Science Foundation for research support, and to Jon F. Frye for his skilled assistance.

1. See J. R. Norsworthy, Michael J. Harper, and Kent Kunze, "The Slowdown in Productivity Growth: Analysis of Some Contributing Factors," in this issue. They attribute 52 percent of the total slowdown in private business productivity to unidentified "other factors." Other recent studies are cited in the same paper.

2. George L. Perry, "Labor Force Structure, Potential Output, and Productivity," $B P E A$, 3:1971, pp. 533-65; William D. Nordhaus, "The Recent Productivity Slowdown," $B P E A$, 3:1972, pp. 493-536; and George L. Perry, "Potential Output and Productivity," $B P E A, 1: 1977$, pp. 11-47. Numerous other studies of the manufacturing sector could be cited; for example, see Christopher A. Sims, "Output and Labor Input in Manufacturing," BPEA, 3:1974, pp. 695-728. 
paper makes no contribution to an understanding of the secular slowdown in productivity, except to add a new cyclical correction of the long-run trend. Its main objective is to examine the short-run behavior of aggregate labor productivity in isolation. In addition to the phenomenon of shortrun "increasing returns to labor" identified in previous studies, it isolates an often overlooked but consistent tendency for productivity to perform poorly in the last stages of a business expansion. In 1956, 1960, 1969, 1973 , and now again in 1979, a productivity shortfall has developed, with absolute declines in the level of productivity occurring in every episode except the first, and in every episode before 1979 the shortfall has subsequently been made up. The paper is more successful in identifying this "end-of-expansion" phenomenon than in explaining it; the results suggest that firms tend consistently to hire more workers in the last stages of a business expansion than is justified by the level of output.

An improved understanding of the short-run behavior of productivity, while of far less importance than an unraveling of the secular slowdown puzzle, nevertheless has relevance for several issues. Any forecast of the paths of employment and unemployment that accompanies a given path of real output over the next few quarters requires a decomposition of recent productivity changes into their permanent and transitory components, as does the early recognition of shifts in the secular growth rate of productivity, and hence of the likely medium-term trends in potential GNP and in the full-employment government budget. Further, the same decomposition is required for structural price equations that attempt to explain the extent to which firms respond to changes in actual labor productivity by altering prices rather than profits. ${ }^{3}$

\section{Alsernative Specifications of the Short-Run Productivity Relationship}

Previous work by Nordhaus, Perry, and others has modeled the procyclical fluctuations in average labor productivity as a partial adjustment

3. My interest in the cyclical behavior of productivity stems originally from the need to distinguish between actual and trend productivity measures for price equations. An hours equation similar to those in table 1 was originally presented in a previous article. See Robert J. Gordon, "Inflation in Recession and Recovery," BPEA, 1:1971, p. 150 . 
of the ratio of aggregate labor hours to potential hours, $H / H^{*}$, in response to fluctuations in the ratio of actual to potential real output, $Q / Q^{*}$ :

$$
\frac{H}{H^{*}}=\left(\frac{Q}{Q^{*}}\right)^{\beta}, \quad \beta<1 .
$$

The assumption that the parameter of adjustment, $\beta$, is less than unity can be interpreted as reflecting the variability of capital utilization and the fixity of some portion of labor input. ${ }^{4}$

The statistical estimation of equation 1 cannot be done until a procedure is developed to construct time series for potential hours and real output. One of the two missing variables can be eliminated if it is assumed that "potential productivity," $Q^{*} / H^{*}$, grows at the exponential trend rate $g$ :

$$
Q^{*}=H^{*} B e^{g t},
$$

where $B$ is a constant term. Perry's estimation procedure has been to use equation 2 to eliminate $Q^{*}$, and then to construct a time series for potential hours. Nordhaus used 2 to eliminate $H^{*}$ and then constructed a time series for potential output. No matter which procedure is chosen, there is no escape from the necessity to select one or the other "potential" series, and thus to impose a criterion for deciding what conditions represent the economy's "potential."

Because I focus in this paper on short-run adjustment, I avoid any discussion of problems involved in constructing potential output measures and instead adopt the series recently constructed by Perloff and Wachter. ${ }^{5}$

4. The traditional explanation of short-run increasing returns to labor is that a portion of labor input is fixed because of training and separation costs. The classic reference is Walter Y. Oi, "Labor as a Quasi-Fixed Factor," Journal of Political Economy, vol. 70 (December 1962), pp. 538-55. More recently Solow has argued that the variable utilization of capital is also necessary to explain the observed facts; see R. M. Solow, "Some Evidence on the Short-Run Productivity Puzzle," in Jagdish Bhagwati and Richard S. Eckaus, eds., Development and Planning, Essays in Honour of Paul Rosenstein Rodan (M.I.T. Press, 1973), pp. 316-25.

5. Jeffrey M. Perloff and Michael L. Wachter, "A Production Function-Nonaccelerating Inflation Approach to Potential Output: Is Measured Potential Output Too High?" in Karl Brunner and Allan H. Meltzer, eds., Three Aspects of Policy and Policymaking: Knowledge, Data and Institutions, Carnegie-Rochester Conference Series on Public Policy, vol. 10 (Amsterdam: North-Holland, 1979), pp. 113-63. See the discussion following their paper for a number of qualifications to the procedures used by Perloff and Wachter. 
Substituting 2 into 1 to eliminate potential hours, I obtain

$$
\frac{H}{Q^{*}}=\left(\frac{Q}{Q^{*}}\right)^{\beta} A e^{-\sigma t},
$$

where $A$ is equal to $B^{-1}$. Equation 3 can be estimated directly, and can be made more flexible by allowing lagged values of the output ratio as well as the current ratio to influence hours, and by allowing for several different time-trends to capture the effect of the slowdown in secular productivity growth.

The period examined here begins in 1954:3. All regression equations are estimated through 1977:4, permitting the use of data for 1978 and 1979 for an evaluation of the aspects of productivity behavior in recent quarters that are not predicted by the regressions. The raw data exhibit the much-discussed slowdown in secular growth rates; in this paper the dividing line initiating the two kinks in the secular trend occurs at 1965:4 and 1972:4. ${ }^{6}$ The respective quarterly growth rates for the three periods, expressed at annual rates, are 2.75 percent for 1954:2 through 1965:4, 1.96 percent for 1965:4 through 1972:4, and 0.85 percent for 1972:4 through 1979:3. Thus the overall slowdown between the first and third periods is 1.87 percentage points.

\section{Regression Equations Relating Hours to Output}

There is no attempt here to estimate the stark and simple version of the hours-adjustment equation represented by 3 . Instead, all the estimates differ from 3 by including three lagged output terms and allowing for a broken time-trend. Rather than estimate three separate time-trends, all equations (except those covering subperiods) contain one time-trend for the entire period, a second trend to measure the extent and significance of a slowdown during 1966:1-1972:4 from the overall trend, and a third trend to measure the extent and significance of a slowdown during $1973: 1-1977: 4$ from the overall trend.

I first estimated the equation using logs of the levels of both dependent

6. Experimentation revealed that the regressions cannot identify a statistically significant slowdown in the 1965-73 period. The 1966:1 breakpoint was chosen to make the results roughly comparable to Norsworthy, Harper, and Kunze, "Slowdown in Productivity Growth." 
and independent variables. ${ }^{7}$ The results are not included in table 1 because a very low Durbin-Watson statistic suggested the presence of positive serial correlation. When the level equation was reestimated with a Cochrane-Orcutt correction, the estimated first-order serial correlation coefficient was 0.883 , suggesting that the relation written in equation 3 should be respecified with the data expressed in first differences. Using lowercase letters to represent quarterly percentage changes, the change equation corresponding to equation 3 is

$$
h-q^{*}=\beta\left(q-q^{*}\right)-g .
$$

The basic first-difference result is presented in column 1 of table 1. An interesting feature of the equation is the statistical insignificance of the 1966-72 secular slowdown. Indeed, this weakness of evidence supporting a slowdown in the period is a consistent characteristic of all the firstdifference equations in this paper.

A serious problem arises with the basic first-difference equation in column 1 that is not evident in the summary statistics presented in the table. Although the Durbin-Watson statistic for the equation is 1.73 , and the Cochrane-Orcutt estimate of the first-order serial correlation is not statistically significant at the 5 percent level, the residuals of the equation display a distinctively nonrandom pattern. The residuals tend to be positive for a number of quarters, followed by a "string" of negative values:

Interval
$1955: 3-1956: 4$
$1957: 1-1958: 2$
$1958: 3-1960: 1$
$1961: 1-1962: 4$
$1965: 2-1968: 2$
$1968: 3-1970: 1$
$1970: 2-1973: 1$
$1973: 2-1974: 3$
$1974: 4-1976: 3$

Fraction of residuals of one sign in interval

\begin{tabular}{cc}
\hline Positive & Negative \\
$5 / 6$ & $\ldots \ddot{6}$ \\
$\ldots$ & $4 / 6$ \\
$5 / 7$ & $\ldots$ \\
$\ldots$ & $7 / 8$ \\
$\ldots$ & $9 / 13$ \\
$7 / 7$ & $\ldots$ \\
$6 / 6$ & $10 / 12$ \\
$\ldots$ & $\ldots$ \\
& $7 / 8$
\end{tabular}

Thus, of the ninety-four observations in this regression equation, seventythree are included in these strings with uniform signs. It is the negatively

7. The estimate of potential nonfarm output is equal to the potential series of Perloff and Wachter for total real GNP, adjusted for the difference between trend growth of nonfarm real GNP and total real GNP over the 1953-79 period. 
Table 1. Estimates of Equation for Aggregate Hours, Nonfarm Business Sector, 1954:3-1977:4 and Subperiods, and Postsample Errors in Predicting Productivity Change $^{\mathrm{a}}$

\begin{tabular}{|c|c|c|c|c|c|}
\hline \multirow{3}{*}{$\begin{array}{l}\text { Independent variable, } \\
\text { summary statistic, and } \\
\text { postsample error }\end{array}$} & \multicolumn{5}{|c|}{ Sample period } \\
\hline & \multicolumn{3}{|c|}{$1954: 3-1977: 4$} & \multirow{2}{*}{$\begin{array}{l}1954: 3- \\
1966: 1 \\
(4)\end{array}$} & \multirow{2}{*}{$\begin{array}{c}1966: 2- \\
1977: 4 \\
(5)\end{array}$} \\
\hline & (l) & (2) & (3) & & \\
\hline \multicolumn{6}{|l|}{ Independent variable } \\
\hline \multicolumn{6}{|l|}{ Time $^{b}$} \\
\hline $1954: 3-1977: 4$ & $-2.48^{\circ}$ & $-2.47^{\mathrm{c}}$ & $-2.48^{c}$ & $-2.48^{c}$ & $\ldots$ \\
\hline 1966-72 slowdown & 0.45 & 0.45 & 0.46 & $\ldots$ & $\ldots{ }^{\mathrm{d}}$ \\
\hline 1973-77 slowdown & $1.42^{\mathrm{c}}$ & $1.40^{\mathrm{c}}$ & $1.42^{\mathrm{c}}$ & $\ldots$ & $\ldots{ }^{d}$ \\
\hline Current $Q / Q^{*}$ & $0.423^{\circ}$ & $0.450^{\circ}$ & $0.457^{\circ}$ & $0.497^{\circ}$ & $0.415^{\mathrm{c}}$ \\
\hline \multicolumn{6}{|l|}{ Lagged $Q / Q^{*}$} \\
\hline One quarter & $0.266^{\circ}$ & $0.269^{\mathrm{c}}$ & $0.270^{c}$ & $0.217^{\mathrm{c}}$ & $0.323^{c}$ \\
\hline Two quarters & $0.100^{c}$ & $0.087^{\mathrm{c}}$ & $0.088^{\mathrm{c}}$ & $0.111^{\mathrm{c}}$ & 0.073 \\
\hline Three quarters & 0.024 & -0.034 & -0.040 & -0.047 & -0.033 \\
\hline Sum of coefficients on $Q / Q^{*}$ & $0.813^{\mathrm{c}}$ & $0.772^{\mathrm{c}}$ & $0.775^{\mathrm{c}}$ & $0.778^{\mathrm{c}}$ & $0.778^{\mathrm{c}}$ \\
\hline \multicolumn{6}{|l|}{ End-of-expansion effect } \\
\hline $1954: 3-1977: 4$ & $\ldots$ & $\begin{array}{r}2.22^{\mathrm{c}} \\
(5.65)\end{array}$ & $\begin{array}{r}1.80^{\mathrm{c}} \\
(4.23)\end{array}$ & $\begin{array}{c}1.57^{\mathrm{c}} \\
(3.21)\end{array}$ & $\begin{array}{r}2.29^{\mathrm{c}} \\
(2.66)\end{array}$ \\
\hline Additional post-1973:1 effec & $\cdots$ & ... & $\begin{array}{r}2.01^{\mathrm{c}} \\
(2.31)\end{array}$ & $\ldots$ & $\begin{array}{c}1.41 \\
(1.22)\end{array}$ \\
\hline \multicolumn{6}{|l|}{ Summary statistic } \\
\hline$R^{2}$ & 0.75 & 0.82 & 0.83 & 0.85 & 0.82 \\
\hline Standard error of estimate & 0.49 & 0.42 & 0.41 & 0.40 & 0.44 \\
\hline Durbin-Watson & 1.73 & 2.13 & 2.27 & 2.33 & 2.14 \\
\hline \multicolumn{6}{|l|}{$\begin{array}{l}\text { Postsample prediction error, } \\
\text { cumulative change in } \\
\text { productivity }\end{array}$} \\
\hline $1977: 4-1978: 4$ & -0.50 & -0.52 & -0.49 & $\ldots$ & -0.55 \\
\hline 1978:4-1979:3 & -1.55 & -0.70 & 0.54 & ... & 0.28 \\
\hline $1977: 4-1979: 3$ & -2.05 & -1.22 & 0.05 & $\cdots$ & -0.27 \\
\hline
\end{tabular}

Sources: Quarteriy hours and output data for the nonfarm business sector are from the U.S. Bureau of Labor Statistics. Potential real GNP for the nonfarm business sector was obtained by applying a quarterly trend adjustment to the series provided by Jeffrey M. Perloff and Michael L. Wachter. See text note 7. The dummy variable representing the end-of-expansion effect is described in the text.

a. The dependent variable is the ratio of aggregate hours to potential real GNP for the nonfarm business sector. The dependent variable and the current and lagged values of the ratio of real GNP to potential GNP, $Q / Q^{*}$, are expressed as quarterly rates of growth. The numbers in parentheses are $t$-statistics.

b. The estimated annual trend rate of growth in productivity is given by the negative of these coefficients summed to the period Indicated. Up to 1966, the coefficient for the entire sample applies; in 1966-72, it is that plus the coefficient for 1966-72; and in 1973-77, it is the coefficient for the entire sample plus the coefficient for 1973-77.

c. Significant at the 5 percent level.

d. The equation for the second subperiod in column 5 includes two constant terms to capture the trend rates of growth. The estimated trends are -2.00 percent a year for 1966-72 and -1.08 percent a year thereafter.

e. Expressed as a percent of the dependent variable. 
correlated zig-zag pattern of the remaining residuals that keeps the Durbin-Watson statistic from accurately revealing the nature of the serial correlation problem in this equation.

This pattern of autocorrelation poses two interesting questions that are relevant to an improved understanding of recent short-run productivity fluctuations. First, can the pattern of residuals be explained by the behavior of some set of economic variables over time? Second, if the pattern of residuals cannot be explained statistically, can it be described in any useful or interesting way?

Initially I assumed that it would be possible to explain the pattern of the residuals by some autoregressive process. For instance, if an inertial process in hiring caused a firm to base hiring plans of the current period on the outcome of the last period, one would expect a significant role to be played by lagged dependent variables. To test this hypothesis, four lagged values of the dependent variable were added to column 1 and every other equation presented in table 1 . In no case was any lagged dependent variable significant, even at the 10 percent level. Another supposition was that firms might make systematic errors in predicting output by basing their expectations on an overly long moving average of past changes in output. But the addition of further lagged values of output to the equations in the table makes no important contribution, except to pick up a seasonal pattern. ${ }^{8}$ These negative findings apply not only to the equations estimated for the full sample period, but also to equations estimated separately for the first and second half of that period.

\section{Specification of the "End-of-Expansion" Effect}

Although it does not appear possible to explain the mysterious residuals in any conventional sense, they can be "characterized" in an appealing and interesting way. Let the last phase of the business cycle expansion begin when the ratio of real GNP to potential real GNP, $Q / Q^{*}$, reaches its peak. Until that time, real output has been rising faster than its long-run trend,

8. Estimates of the equations with eight lagged output terms were presented to the Brookings panel, and several participants commented that the significant zig-zag pattern of the weights on lags four and five might be a reflection of seasonality in the underlying data. As many as sixteen lags were also included with no improvement in fit. 
and thus business firms may have discovered that their real sales have outstripped their previous plans and expectations, requiring upward revisions of plans for both hiring and capital investment. Managers of individual firms, each buoyed by a series of quarters when business was better than expected, may feel justified in extrapolating this performance into the future. Given the economy's limited capacity to produce, the realization of each of their plans in some episodes would have required that each firm simultaneously raise its market share.

A dummy variable can be created that captures this end-of-expansion effect. Each episode of overhiring is constrained to commence in the quarter after the peak quarter of $Q / Q^{*}$, which for the five business cycles since $1954: 2$ has occurred in 1955:4, 1959:2, 1968:3, 1973:1, and 1978:4. ${ }^{9}$ Because it is assumed that managers eventually recognize that they have too many employees on the payroll and take corrective measures, the dummy variable is constructed to take positive values for $M$ quarters following the quarters when $Q / Q^{*}$ reaches its peak, and thereafter to take negative values for $N$ quarters. The variable is constrained to sum to zero over any given business cycle, and thus does not distort the meaning of the secular trend coefficients in the hours equations. An additional constraint is imposed by setting the values of $M$ and $N$ equal to the same number for each cycle: six quarters for the $M$, eight quarters for $N .{ }^{10}$ The larger value of $N$ reflects the tendency of firms to take their corrective action over a longer period than the time taken for the overstaffing problem to occur.

Column 2 in table 1 illustrates the effect of adding the "end-of-expansion" (EOE) dummy variable to the equation in column 1. The dummy variable is extremely significant statistically, with a $t$-statistic of $5.65 .{ }^{11}$ The variable is defined so that its coefficient indicates the cumulative percentage amount of overhiring that occurred on average over all cycles; during the six quarters of overhiring $(M=6)$ hours reached a level 2.22 percent higher than can be explained by the behavior of current and lagged

9. To date, the National Bureau of Economic Research has not yet declared the existence of a recession in 1979. Nevertheless, it seems likely that a recession will begin late in 1979 or early in 1980, and that in retrospect 1978:4 will represent the peak in $Q / Q^{*}$. The three quarters of 1979 all had $Q / Q^{*}$ values significantly below that in 1978:4.

10. The only exception to the statement made in the text is that, reflecting the shorter and sharper business cycle for the mid-1950s, $M=4$ and $N=6$ for the period beginning with the $Q / Q^{*}$ peak in 1955:4.

11. Exact values of $t$-statistics are shown in table 1 only for the EOE variables; the significance of other variables is indicated in the notes to the table. 
output, and this excess of 2.22 percentage points was gradually eliminated over the subsequent eight quarters $(N=8) .{ }^{12}$ Note that the estimates of the coefficients on secular trends are virtually unaffected by the introduction of the EOE variable in column 2. The sum of the coefficients on current and lagged output is about the same in both columns 1 and 2 and indicates only a partial response of hours, the effect known as short-run increasing returns to labor. Thus the fitted coefficients in equation 2 combine the traditional procyclical fluctuations in labor productivity together with an indication of unusual weakness in the last stage of the business expansion.

Several additional equations are presented in table 1 to determine whether the significance of the EOE effect is attributable to a particular business cycle, or rather reflects a phenomenon that operates during each cycle. Column 3 is identical to column 2 but allows a separate value of the EOE variable to enter after 1973:1. The coefficient on this variable would be zero if the behavior of productivity during the 1973-74 episode were the same as the average of the previous cycles, and would be positive if there were a greater tendency toward excess staffing and slack productivity in that episode. It is apparent that the 1973-74 episode was unusual because it had a cumulative excess hiring of 2.01 percentage points over the "normal" EOE effect of 1.80 percent, for a total of 3.81 percent. Despite this feature of the 1973-74 period, the coefficient on the overall EOE effect drops only slightly in moving from column 2 to 3 , and its $t$-statistic is still a robust 4.23 .

Columns 4 and 5 of table 1 report the results obtained when the sample period is divided, with separate estimates for the 1954:3-1966:1 and 1966:2-1977:4 periods. The results for the divided sample make the 1974 episode look less unusual. In column 5 the coefficient on the additional 1973-74 EOE effect is reduced to 1.41 percent, with a $t$-statistic of only 1.22 , which is below the 10 percent level of significance. Despite the isolation of the 1968-69 and the 1973-74 periods in column 5, there still seems to be a significant end-of-expansion effect in column 4 for the first half of the sample period. The productivity slump of 1956 has long stood as evidence that the simple procyclical story of equation 1 is an incomplete representation of the short-run behavior of productivity; a similar cessation in productivity growth occurred in the next business cycle

12. For example, the dummy variable is defined as one-sixth for the first six quarters following 1968:3 and as minus one-eighth for the subsequent eight quarters. 
expansion after the $Q / Q^{*}$ peak was reached in 1959:2. The excellent performance of productivity during the first two years of the Kennedy administration can thus be partly explained through the normal working of the "rebound" phase of the end-of-expansion effect.

\section{Attempting to Explain the End-of-Expansion Effect}

Thus far I have only described the end-of-expansion effect, without providing any behavioral explanation of its origins. To address the question of how much of the sluggish response of aggregate hours at the end of business expansions comes from employment and how much from hours per employee (HPE), separate regression equations were estimated corresponding to each column of table 1 in which employment and HPE alternatively replaced aggregate hours as the dependent variable. Of a total EOE effect of 1.80 percentage points (corresponding to the equation for the entire period in column 3 of table 1), 1.26 points are contributed by employment and 0.54 point by HPE. Thus it would appear that the EOE phenomenon primarily involves the maintenance of an excessive number of employees relative to output, with hours per employee making a minor additional contribution. ${ }^{13}$

Several suggestions have been made to explain the EOE phenomenon as being consistent with rational profit-maximizing behavior. One is that labor and capital may be interdependent factors of production. In periods when capital investment is relatively high, additional employees may be required to install new equipment, and experienced employees may have to work overtime to train new employees. These "installation costs" decrease when investment is low. To test this proposition, the detrended ratio of fixed nonresidential investment to potential GNP was entered into the basic equation (column 3 ) in the form of both its level and first difference. The $t$-statistics were minuscule, and the size of the EOE coefficients was not affected.

A second suggestion is that firms maintain some slack in their labor force when the quit rate is high to guard against being caught short-

13. A further indication that most of the EOE effect stems from employment rather than from HPE is the high $t$-statistic of 3.89 on the EOE variable in the employment equation, as opposed to one of only 1.17 in the HPE equation. After 1973:1, employment and HPE each make an equal contribution of about 1 percentage point, with $t$-statistics that are marginally significant at the 10 percent level. Similar results were obtained when equations were run for the two subperiods. 
handed. This slack subsequently disappears during periods when the quit rate is low and firms no longer are concerned that key employees may depart. Both the level and first difference of the quit rate in manufacturing were added to the basic equation in column 3 with the same negative outcome as that of investment; $t$-statistics were below the margin of significance, while the EOE coefficients were unaffected.

A final set of tests investigated the statistical legitimacy of the form of the equations in table 1 . In principle, the relationship between output and hours could be tested with either hours or output on the left-hand side of the equation to be estimated. Following the procedure employed by Christopher A. Sims in his previous investigation of manufacturing productivity, an alternative equation was estimated with the rate of change of output on the left, and leading as well as current and lagged changes in hours on the right. ${ }^{14} \mathrm{~A}$ symmetric equation was estimated that adds leading values of output change to column 3 of table 1 . The results are completely consistent with the view that output is exogenous with respect to hours; leading values of hours had large and significant coefficients in the output equation, but leading values of output had insignificant coefficients in the hours equation. A satisfying feature of this additional set of tests is that the EOE variables are strongly significant (and of course with the opposite sign) when the relationship is estimated with output change as the dependent variable. ${ }^{15}$

\section{Interpreting the 1978-79 Productivity Performance}

The last three rows of table 1 list the postsample extrapolations of the equations. All equations except that in column 3 predict a growth rate of

14. For additional discussion of the interpretation of these techniques, see Sims, "Output and Labor Input in Manufacturing." In my tests only two leading quarterly values were included, in contrast to the larger number of leading values included in Sims' study of monthly data. The only significant coefficient on a leading value of output in the hours equation occurred with a two-quarter lead, but the coefficient had a negative sign.

15. George Perry has inquired whether the EOE effect might be explained in part by the cyclical mix of output. One would expect productivity growth to fall and employment to appear too large in years when the output of industries with high productivity like automobiles is falling. While declining automobile sales may be part of the problem in 1973-74, the timing is wrong in earlier cycles. For instance, auto sales fell sharply between 1965 and 1966-67 and between 1969 and 1970, yet the EOE effect only shows up in 1969 and not in 1966. 
hours during 1978-79 (last row) that is smaller than the actual outcome, and thus a higher level of productivity than has actually occurred. The forecast errors become successively smaller as one moves from column 1 to column 3, and the error remains small in column 5. The equations in columns 3 and 5, which include the post-1973:1 dummy, predict a larger decline in productivity for the 1978:4-1979:3 period than has actually occurred. The ability of these equations to "track" the precipitous decline in the level of productivity during the first half of 1979 results from the impact of the EOE effect (which first takes place in 1979:1), as well as from the fact that, in those predictions, the additional 1973-74 effect also applies to $1979 .{ }^{16}$

In figure 1 the actual values of the level of nonfarm productivity between 1967 and 1979 are compared with the predictions of levels implied by the fitted values of two equations for the growth rate of productivitythe simple equation presented in column 1 , table 1 , reestimated for the 1966-77 period and shown as the dotted line, and the equation in column 5 incorporating the EOE effect that was estimated for the same sample period and shown as the dashed line. A comparison of the dashed and dotted lines illustrates the role of the EOE effect in improving the explanation of the absolute decline in productivity in 1969 and 1973-74, as well as the subsequent rebound in 1970-72 and 1975-76. The postsample extrapolation of the dashed line also captures the decline in productivity during the first half of 1979 , although its level is between onehalf and one percentage point too high throughout 1977, 1978, and 1979, suggesting that a third slowdown in the secular trend may have begun in early 1977.

\section{Implications of the results}

The coefficients of dummy variables in regression equations cannot explain puzzling phenomena, but they help to identify and describe some interesting features of economic behavior. In previous work I tested the significance of dummy variables for the 1971-74 price controls and subsequent postcontrols rebound as an aid in describing U.S. price behavior, and "wage-push" dummy variables in wage equations for various

16. Even the unadorned first-difference equation in column 1 predicts an absolute decline in productivity during the first half of 1979 because of the impact of rapid growth of output in 1978 on hiring in 1979 through the lagged output terms. 
Figure 1. Output per Hour in the Nonfarm Business Sector, Actual and Predicted from Alternative Equations, 1967:2-1979:3

$1967: 2=1.00$

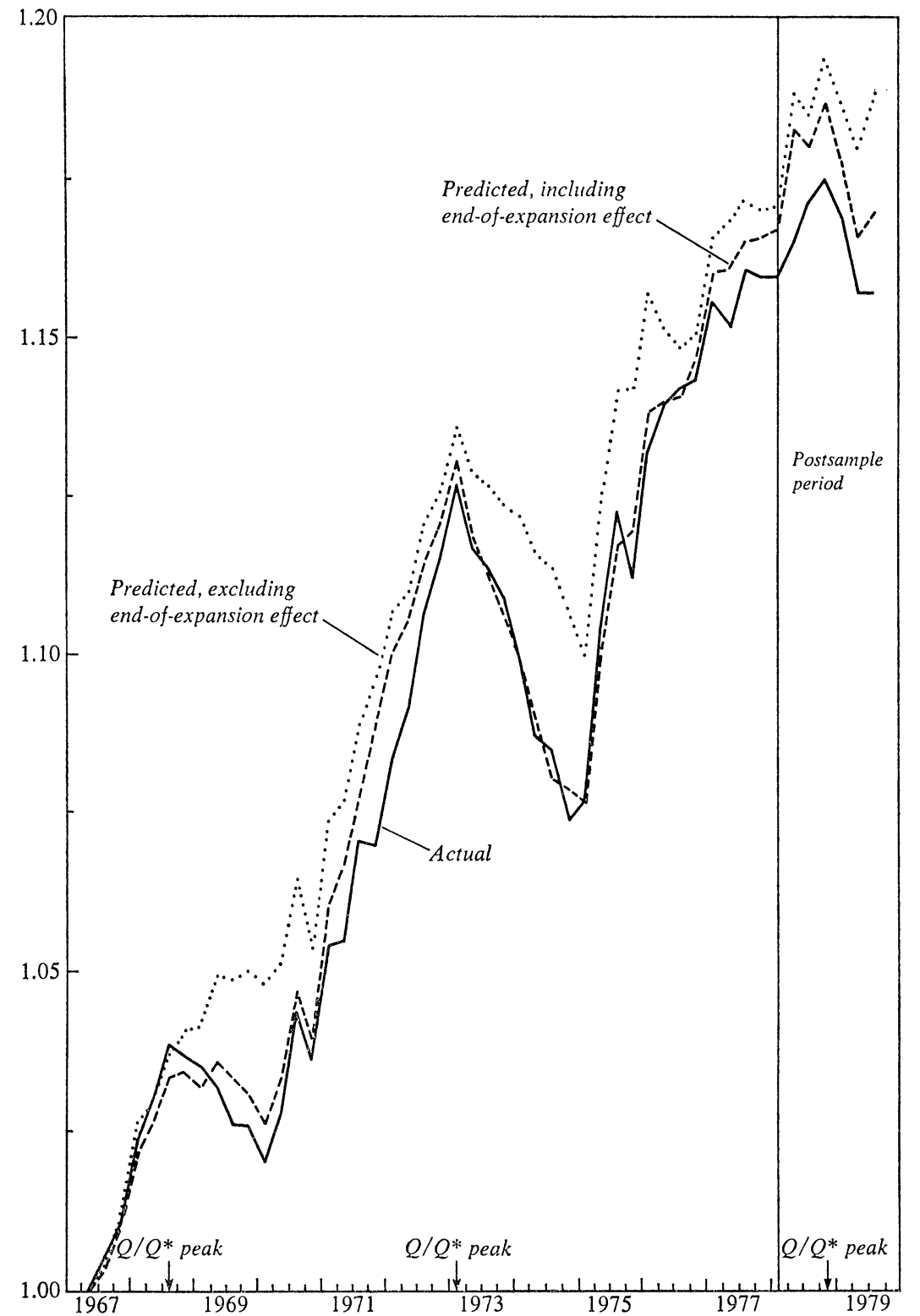

Sources: Actual-same as table 1; estimated-implied from fitted values of the equations in columns 1 and 5 of table 1, with the column 1 equation reestimated for the 1966-77 period.

a. The variable $Q / Q^{*}$ is the ratio of real output to potential real output. 
European countries. ${ }^{17}$ In each case, an external event could be identified by contemporary accounts to help date and describe the phenomenon captured by the dummy variables. In this paper, the end-of-expansion dummy variables are statistically significant and operate consistently across business cycles, but their interpretation is more conjectural. My conjecture is that the phenomenon stems from mistaken expectations and from inertia in changing personnel budgets. Although no direct evidence is presented here that misperceptions actually occurred, the data are consistent with my imposed constraint that the dummy variable sums to zero, thus forcing any end-of-expansion overstaffing to be eliminated in subsequent periods.

One might liken the EOE effect to other phenomena in economic timeseries involving overshooting-including booms in the stock market and overbuilding in the commercial construction industry. Yet at a deeper level, these two examples of overshooting are different in nature. Participants in the stock market deal in an auction market in which there is no inertia beyond the expectations of other market participants to limit price movements, and no external guidepost exists to indicate a "correct" level of prices. Expectations in September 1929 were incorrect only ex post and did not appear so at the time. In commercial construction, however, overbuilding may result from the long lags between decisionmaking and project completion, imparting an inertia to the time-series on nonresidential construction that is familiar to students of business cycles. The end-of-expansion phenomenon of overstaffing may result from a similar lag between business decisions that set personnel budgets and the actual hiring, training, and promotions. Business firms may not be irrational or even guilty of mistaken expectations at the time that the personnel budgets are set. Rather, they may gradually recognize an overstaffing condition but be unable to correct it rapidly because of both the high costs of more frequent decisionmaking and the inevitable time it takes to prune the work force purely by attrition when layoffs are costly.

At the more immediate level of current policy discussions, the results in this paper suggest that standard equations may tend regularly to overpredict productivity growth during the interval following the cyclical peak in the ratio of actual to potential output. A corollary is the tendency for

17. See Robert J. Gordon, "Can the Inflation of the 1970s be Explained?" $B P E A$, 1:1977, pp. 253-77, and "World Inflation and Monetary Accommodation in Eight Countries," BPEA, 2:1977, pp. 409-68. 
simple versions of "Okun's law" to fail to explain why unemployment remains so low and employment so high at the end of expansions and the beginning of contractions. ${ }^{18}$ Thus current forecasts based on conventional productivity equations may be unduly pessimistic about the increase in unemployment that will occur during late 1979 and early 1980, but overly optimistic for subsequent periods.

\section{Discussion}

Both William Poole and Robert Hall pointed out that an "end-of-expansion" effect could only characterize the data ex post. That effect could not characterize the decision process of businesses in hiring, however, because businesses could not know the expansion was ending. Hall reasoned that lags in the hiring process must lie at the heart of the productivity shortfalls that Robert Gordon identifies.

Charles Holt asked for more work on the theoretical aspects of the hiring and employment process that might explain Gordon's productivity variables. He reasoned that high turnover rates could cut into productivity because they required more training and on-the-job learning and also because they led employers to keep a larger buffer of workers on the payroll and made it more difficult for them to correct hiring mistakes because layoffs were low. Such a process might fruitfully be tested more thoroughly than Gordon had been able to do in this paper. Lacking any convincing explanation for the dummy variables in the regressions, several participants, and Gordon himself, emphasized that those variables describe an interesting phenomenon rather than explain it.

18. Arthur Okun is well aware of this problem and in fact has explained the low level of unemployment in 1974 in these terms: "I believe that the principal explanation lies in the momentum and overoptimism of personnel policies." See Arthur M. Okun, "Unemployment and Output in 1974," BPEA, 2:1974, p. 503. 